\title{
El revés del mapa. Notes al voltant de Brian Harley i Franco Farinelli
}

\author{
Bernat Lladó Mas \\ Universitat Autònoma de Barcelona \\ Grup de Geografia i Gènere. Grup d'Estètica i Política (GEP21) \\ bernat.llado@gmail.com
}

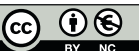

Recepció: març de 2011

Acceptació: maig de 2011

\section{Resum}

A finals de la dècada de 1980, Brian Harley utilitza la filosofia de Jacques Derrida per «desconstruir el mapa», però si bé la seva proposta teòrica fou molt innovadora, no esgotà totes les implicacions d'aquella filosofia, especialment en relació amb el signe cartogràfic. Tot i que el també geògraf Franco Farinelli no ha utilitzat mai l'expressió «desconstruir el mapa» per referir-se a la seva crítica a la raó cartogràfica, existeixen alguns paral-lelismes entre aquesta crítica i la desconstrucció de Derrida. Fins i tot, i aquest és l'argument central del text, podem aventurar que ha estat Farinelli qui ha portat més enllà una possible desconstrucció del mapa, encara que, com es veurà, en algun punt de la seva crítica es reprodueixen algunes oposicions binàries que justament la filosofia de Derrida havia volgut desconstruir.

Paraules clau: Brian Harley; Franco Farinelli; desconstrucció; raó cartogràfica.

Resumen. El revés del mapa. Notas sobre Brian Harley y Franco Farinelli

A finales de la década de 1980, Brian Harley utiliza la filosofía de Jacques Derrida para «deconstruir el mapa». Si bien es cierto que su propuesta teórica fue muy innovadora, no agotó todas las implicaciones de aquella filosofía, especialmente en relación con el signo cartográfico. A pesar de que el también geógrafo Franco Farinelli nunca ha utilizado la expresión "deconstruir el mapa» para referirse a su crítica a la razón cartográfica, existen algunos paralelismos entre esta crítica y la deconstrucción de Derrida. Incluso, y este es el argumento central del texto, podemos aventurar que ha sido Farnelli quien ha llevado más lejos una posible deconstrucción del mapa, a pesar de que, como se verá, en algún punto de su crítica se reproducen algunas oposiciones binarias que justamente la filosofía de Derrida pretendía deconstruir.

Palabras clave: Brian Harley; Franco Farinelli; deconstrucción; razón cartográfica.

Résumé. Le revers de la cartographie. Remarques sur Brian Harley et Franco Farinelli

À la fin des années quatre-vingt, Brian Harley utilise la philosophie de Jacques Derrida pour «deconstruir la carte». Bien qu'il soit certain que sa proposition théorique a été très innovatrice, il n'a pas vidé toutes les implications de cette philosophie, spécialement en 
relation au signe cartographique. Malgré que Franco Farinelli, aussi un géographe, n’a jamais utilisé l'expression «deconstruir la carte» pour se rapporter à sa critique à la raison cartographique, quelques parallélismes existent entre cette critique et la déconstruction de Derrida. Même, et c'est l'argument central du texte, nous pouvons risquer que c'était Farinelli qui a porté plus loin une déconstruction possible de la carte, malgré le fait que, comme il sera vu, dans un point de sa critique se reproduisent quelques oppositions binaires auxquelles justement la philosophie de Derrida prétendait deconstruir.

Mots clé: Brian Harley; Franco Farinelli; déconstruction; raison cartographique.

\begin{abstract}
The reverse of the cartography. Notes on Brian Harley and Franco Farinelli
At the end of the eighties, Brian Harley uses Jacques Derrida's philosophy for «deconstructing the map». Though it is true that his theoretical proposal was very innovative, it did not exhaust all the implications of that philosophy, especially in relation to the cartographic sign. In spite of the fact that Franco Farinelli has never used the expression «deconstructing the map» to refer to his critique to the cartographic reason, some parallelisms exist between this critique and Derrida's deconstruction. Even, and this one is the central argument of the text, we can suppose that it has been Farinelli who has taken a possible deconstruction of the map further. However, as it will be shown, at some point of his critique some binary opposition are reproduced like Derrida's philosophy was trying to deconstruct.
\end{abstract}

Key words: Brian Harley; Franco Farinelli; deconstruction; cartographic reason.

\title{
Sumari
}

1. Desplegar el mapa 4. Plegar el mapa

2. Terroritzar els cartògrafs

5. Referències bibliogràfiques

3. Dibuixar una línia

\section{Desplegar el mapa}

Avui en dia, el concepte de cartografia s'ha ampliat tant que hi podem trobar totes les disciplines imaginables: des de la literatura comparada fins a la filosofia, passant per l'art i la sociologia crítica, entre d'altres (Weigel, 2009; Cosgrove, 2005; De Sousa Santos, 2000; Crampton, 2002; Alonso, 2006). És difícil situar el moviment general que ens ha portat fins aquesta situació. Alguns autors com Edward Soja, per comoditat, utilitzen l'expressió «gir espacial» per referir-s'hi (Benach i Albet, 2010), però no podem estar segurs de si ha estat la geografia qui ha obert les portes per fer passar la resta de disciplines socials i humanes o són aquestes qui, contràriament, han adoptat una sensibilitat geogràfica particular. Possiblement, totes dues coses són certes. Perquè, de la mateixa manera que es parla d'un "gir espacial» o "topogràfic» en el si del camp de les humanitats, també podríem afirmar que, des de fa uns quants anys, alguns geògrafs i geògrafes han reivindicat el paper de la filosofia, la història, la sociologia o la teoria literària, per pensar algunes qüestions pròpies de la nostra disciplina. 
Brian Harley i Franco Farinelli es poden incloure en aquest darrer grup. Tots dos, des de tradicions i interessos diversos, han establert un diàleg més o menys constant, més o menys enriquidor, amb sabers afins a la geografia; molt especialment amb la filosofia. Per això, en el text que segueix, voldríem restablir aquest diàleg, a fi d'il.luminar algunes de les propostes més originals que, al nostre parer, han sorgit en el camp de la història de la cartografia i la geografia en els darrers temps (Pickles, 2004; Klinghoffer, 2006; Crampton, 2010). I, especialment, recuperar una expressió que, si bé darrerament ha perdut la seva força inicial, permet relacionar-los tots dos. En efecte, «desconstruir el mapa», el lema que utilitzà Harley a finals dels anys vuitanta seguint l'obra del filòsof francès Jacques Derrida, és una expressió que ens serveix de fil argumental per vincular-lo a Franco Farinelli. Si bé, cal dir-ho d'entrada, aquest darrer en cap moment utilitza aquesta expressió. Amb tot, però, la crítica a la raó cartogràfica del geògraf de Bolonya comparteix alguns trets que ens permeten afirmar que, en termes generals, també ha dut a terme una desconstrucció del mapa.

Fins i tot podríem dir — aquesta és la tesi que volem defensar- que, malgrat que va ser Brian Harley qui s'apropià del lema, és Franco Farinelli qui ha portat més lluny una desconstrucció del mapa. Amb això no volem desmerèixer el primer; ni tampoc entrar en el joc de saber qui dels dos és més fidel a l'esperit de la lletra. Més aviat ens sembla que, prenent com a punt de partida la noció "desconstruir el mapa", no només podem relacionar dos dels geògrafs més influents de les darreres dècades, sinó també aclarir, d'una banda, en què pot consistir això de la desconstrucció i, de l'altra, donar forma a una nova manera d'entendre la cartografia i la seva història.

\section{Terroritzar els cartògrafs}

«Potser [els cartògrafs] quedaran terroritzats davant la menció de la desconstrucció» (Harley, 2005a: 190). Amb aquesta frase tan provocadora, Brian Harley anticipava l'inici d'una suposada ruptura en el si de la historiografia cartogràfica. Fos certa o no, gràcies a un llenguatge al mateix temps polèmic $\mathrm{i}$ senzill, el geògraf britànic aconseguia un important ressò, no només en el camp de la cartografia, sinó també en el conjunt de les ciències humanes. L'article sobre la desconstrucció del mapa de Brian Harley es publicà en un moment molt oportú. A finals dels anys vuitanta, en el si de la geografia dominant, es vivien una sèrie de debats que, amb el temps, ens hem acostumat a anomenar "postmoderns». I un d'aquests debats se centrava en l'aplicació i la traducció d'un conjunt d'idees, arguments, filosofies, llibres i autors conegut amb el nom de "postestructuralisme» en el camp de la geografia. A l'interior d'aquest ampli moviment, hi sobresortien dos autors francesos, Michel Foucault i Jacques Derrida (Lechte, 2010).

És el darrer d'aquests autors que associem amb la desconstrucció, i és també a partir d'ell que Brian Harley suggereix una nova «filosofia de la història de la cartografia». Sovint, s'ha definit la desconstrucció com una "estratègia»; 
una manera d'abordar determinades qüestions relacionades amb la textualitat. Però no és, de fet, ni una metodologia pròpiament, ni tampoc cap epistemologia, és a dir, no és cap camí prèviament traçat i encara menys un lloc d'arribada. Estrictament parlant, sembla més aviat un estil propi de lectura; la lectura (i escriptura) creativa que el propi Derrida realitza d'alguns textos de la tradició filosòfica i literària. En termes generals, podria ser la continuació del projecte heideggerià d'una Destruktion de la metafísica occidental (De Peretti, 1997; Abbagno, 2008). Per aquest motiu, a primera vista, es fa difícil saber com es podria traslladar aquesta estratègia textual o aquesta "genealogia estructurada", per dir-ho com el mateix Derrida, dels diferents conceptes que orienten el pensament occidental, al camp de la història de la cartografia. Amb tot, és el pas que realitza Brian Harley.

Evidentment, no és un pas segur ni tampoc complet, però, en qualsevol cas, és atrevit i, fins i tot, necessari. Per Harley, la desconstrucció del mapa ens permetria «trencar el suposat vincle entre la realitat i la representació que ha dominat el pensament cartogràfic» (Harley, 2005a: 187-188). Un vincle que pressuposava una realitat immediata i totalment present, d'una banda, i una representació que es limitava a restituir aquella realitat, de l'altra. Doncs bé, és justament aquest pressupòsit allò que la desconstrucció desmenteix. Per desenvolupar-ho, ens podem valer del signe semiològic. Per Paul Zumthor, el mapa «és globalment un signe» i, pel mateix Derrida, la qüestió del signe és cabdal per entendre la desconstrucció (Zumthor, 1994: 305; Derrida, 1977: 23-47). D'aquí que sigui pertinent relacionar una cosa amb l'altra.

A grans trets, l'argument és el següent. Si bé la semiologia (de Ferdinad de Saussure en endavant) contribuí en gran mesura a desmitificar el presumpte vincle natural $i$ espontani entre el signe i la cosa designada, aquella — segons Derrida - no aconseguí tancar el cicle de la metafísica. Perquè l'estructura del signe, la partició binària entre el significant i el significat, estava encadenada a una constel.lació de dicotomies d'un abast més profund i llunyà que calia situar en els orígens de la metafísica occidental. D’una banda, Martin Heidegger ja havia advertit que el Ser de les coses s'identificava amb la seva presència - $\mathrm{i}$ per això utilitzava l'expressió «metafísica de la presència». De l'altra, Derrida recalcava que aquesta concepció del Ser depenia d'haver privilegiat la veu, la parla, el diàleg, per damunt del signe escrit -i també per això, en comptes de «metafísica de la presència», utilitzava el terme una mica dadaista de fonocentrisme (Asensi, 2004). El problema, però, no seria tant el fet d'haver organitzat les coses per mitjà de parelles binàries, sinó haver privilegiat un dels dos termes. Haver-los distribuït de forma jeràrquica (Ferraris, 2006). La determinació del Ser com a presència, el domini de la veu, formarien l'estructura sobre la qual s'aixeca un ordre binari on un dels dos termes és l'element original, present, positiu, mentre que l'altre no seria res més que un concepte derivat i secundari.

Això és el que succeeix en el cas del signe. La semiologia, com bé apuntava Brian Harley, hauria trencat el vincle entre realitat i representació, però hauria continuat mantenint la jerarquia que fa prevaler el significat sobre el significant (i això, segons Derrida, perquè Saussure hauria seguit el model fonètic de la 
llengua, entenent així l'escriptura com una cosa auxiliar i secundària). El filòsof francès el que fa és capgirar la jerarquia —ara el terme positiu és el significant-, per després afirmar que l'un i l'altre són indecidibles, és a dir, que no es pot assegurar quin dels dos és anterior a l'altre, més original que l'altre. Primer fa giravoltar els termes de la jerarquia, però fent només això es deixa intacte la jerarquia en si (la / de la metafísica, segons Manuel Asensi). Convé un pas més: la invenció d'un "concepte límit» que vagi més enllà de l'oposició i la "vertical d'autoritat" (Ferraris, 2006; Jenkins, 2006). Traça, cendra, differánce, petjada, tots són per Derrida termes més apropiats que el de signe (Derrida, 2003). Per tant, si seguim tot aquest argument, hauríem de dir que el mapa és globalment una traça — un dispositiu el significat del qual no és mai del tot present.

Certament, Brian Harley no porta tan lluny la desconstrucció del mapa (Belyea, 1992). Reconeix el fet que no existeix un vincle privilegiat entre la realitat i el mapa. A partir d'aquí, pot qüestionar la distinció entre mapes propagandístics i mapes que no ho són, entre retòrica i ciència del mapa. Un gest molt proper a la desconstrucció que Derrida realitza de la parella binària entre sentit literal i sentit metaforic (Derrida, 1989; Goldschmit, 2004). A més, la historiografia cartogràfica que proposa Harley vol allunyar-se de la tradicional concepció metafísica d'aquesta, que és lineal, acumulativa i homogènia, és a dir, una història de les tècniques, els instruments, els avenços i els progressos que ens haurien conduït des d'una representació simbòlica fins a una altra d'objectiva seguint unes etapes que s'apilonen les unes sobre les altres com caixetes estanques i unitàries (Derrida, 1977; Jenkins, 2006).

Finalment, Harley també replanteja allò que és central i marginal en la història dels mapes. Per ell, una estratègia desconstructiva ha d'estar al cas dels «marges del text». Per això escriu: «Les portades decoratives, les lletres, les targetes, les vinyetes, les dedicatòries, les roses dels vents i els marges que puguin incorporar motius del vocabulari de l'expressió artística contribueixen a reforçar els significats polítics [del mapa] [...]. Vist d'aquesta manera, el concepte de decoració cartogràfica com un exercici estètic marginal esdevé antiquat» (Harley, 2005b: 104). De fet, aquesta lectura d'allò aparentment marginal, d'aspectes a simple vista periferics, és pròpiament una acció desconstructiva (Salanskis, 2009). Per David Hoy, Derrida s'interessaria no tant per les idees o els arguments principals d'un text, sinó per les seves «metàfores marginals» o altres «recursos teòrics» als quals normalment no es dóna importància (Hoy, 1988). I per un autor com Marc Goldschmit, el filòsof francès és qui més ens ha ensenyat «a qüestionar sistemàticament les vores, els marges, els títols d'un text, i a reinscriure aquestes marques en el [propi] text» (Goldschmit, 2004: 9). Per tant, desconstruir la parella binària marginal/central és una tasca pròpia de l'estratègia desconstructiva; i també ho és establir connexions inesperades entre sons fonètics, imatges gràfiques, etimologies 0 relacions semàntiques (Culler, 1998: 126; Ramond, 2009). Això darrer, sens dubte, és un exercici molt propi del treball de Franco Farinelli, com comentarem més endavant. I per acabar, alguns autors han identificat el "parergon» (un tecnicisme de Derrida) com allò que és accessori, «el detall exterior que 
davant la mirada micrològica es torna una instància clau per definir una obra» (Peñalver, 1989: 17; Asensi, 2004: 19).

Amb tot, com hem dit, Harley no porta gaire més lluny la seva desconstrucció del mapa. Si bé aquest autor afirmà que la cartografia no només consisteix a fer mapes, sinó a construir mons, majoritàriament continuà concebent-los "com a representacions gràfiques del món", en paraules de Barbara Belyea (Harley, 1990: 16; Belyea, 1992: 2; Lilley, 2004). I, per tant, mantenint la jerarquia binària que atribueix a la realitat (el significat) una presència original en relació amb la representació (significant). Així les coses, i a manera de resum, Harley introduí d'una forma brillant i didàctica el debat postestructuralista en el camp de la cartografia seguint els termes de la geografia postmoderna angloamericana dominant en aquell moment. A partir d'autors com Michel Foucault i Jacques Derrida, plantejà d'una manera nova qüestions com ara el poder intern i el poder extern dels mapes, la «textualitat», la retòrica i el seu contingut ideològic. Ara bé, la seva desconstrucció del mapa no trastocà de manera general el signe cartogràfic, que continuà mantenint una organització estructural binària $\mathrm{i}$ jerarquitzada $\mathrm{i}$, per tant, confinat a la tradició pròpia de la «metafísica de la presència». Haurem d'esperar les igualment oportunes contribucions de Franco Farinelli per sortir parcialment d'aquesta tradició.

\section{Dibuixar una línia}

Ja hem dit que Franco Farinelli no utilitza el terme desconstrucció ni tampoc cita Jacques Derrida com un autor d'inspiració principal —si bé, certament, és un autor que acostuma a aparèixer en els seus escrits. Tampoc, que jo sàpiga, en cap moment el mateix Farinelli ha definit el seu treball en termes d'un projecte general de l'estil «en els darrers anys he mirat de fer això, o això altre; d'estudiar la història de la cartografia d'aquesta manera, o d'aquesta altra». Amb tot, em sembla que si prenem com a punt de partida els breus apunts anteriors sobre la desconstrucció del mapa, podem determinar alguns trets generals del seu treball com un projecte particular — tant si després ho anomenem desconstrucció del mapa com si no- $\mathrm{i}$, al mateix temps, aillar alguns gestos menors propis d'una estratègia desconstructiva.

L'afirmació recorrent de Farinelli, segons la qual, des de l'origen de la cultura occidental, «el món és la còpia del mapa, i no al revés», és, al nostre entendre, un primer pas vers la seva desconstrucció (Farinelli, 2002: 226). Perquè l'element al qual solem atribuir un valor original, precedent, assumeix pel geògraf de Bolonya un caràcter secundari i derivat. Tornant al llenguatge de la semiologia: en aquest cas, és el significant el terme positiu —al principi, hi havia el mapa, ens vol dir aquest autor. Certament, Farinelli fa giravoltar la relació estructural i jeràrquica del signe. Amb tot, li falta un pas: convertir el signe en cendra, transformar-lo en una simple traça. Perquè només capgirant els valors de la jerarquia, aquesta no s'elimina, com hem vist. El mapa entès globalment com una traça vol dir: el territori i el mapa, significat i significant, són indistingibles, estan mútuament implicats. No podem dir quin dels dos 
precedeix l'altre, què és la còpia de què, on cal anar a buscar el simulacre i on trobarem la realitat. En canvi, aquest últim pas és el que Farinelli descuida, perquè manté intacta la barra, la línia que separa les dues cares del signe i les escindeix.

«Dibuixar línies —escriu John Pickles— és un acte geogràfic i espacial fonamental a través del qual les identitats s'inscriuen i el logos del pensament occidental és fundat» (Pickles, 2004: 3).

Que, a través de fronteres, classificacions, llegendes, colors o volums, conformem identitats és una cosa clara i evident: a través de l'escriptura (el «traçat») definim una realitat que en si és inestable, gradual, dinàmica o caòtica, fins i tot. Amb la pràctica cartogràfica, nosaltres la fixem; que això ens sigui pràctic, a més de polític, ja és una altra cosa, però, d'entrada, ja hem fixat un marc que després pot ser molt difícil de canviar. Quan aquest marc es «naturalitza» i es confon amb alguna cosa essencial - la filosofia en diu un Transcendental, és a dir, que té un valor per si mateix-, i no el resultat d'una diferència, aleshores el dispositiu cartogràfic ha tingut èxit. Fet i fet, diu Farinelli seguint Lord Baden-Powell, «L'Índia no existeix» (Farinelli, 2001a: 9).

Allò que no és tan evident és que, a través de l'acte cartogràfic de dibuixar línies, com diu Pickles, s'hagi fundat el logos occidental. Paraula polisèmica d'origen grec, el logos significa, en el context de la discussió filosòfica, «el racional, el principi intel-ligible, l'estructura o l'ordre que presideix qualsevol cosa, o la font d'aquest ordre, o l'explicació d'aquest ordre» (Dent, 2008: 719). Sembla que l'origen d'aquest ordre - la manera que tenim a Occident d'organitzar el món- el trobaríem, segons el filòsof Martin Heidegger, com hem vist, en una oposició bàsica entre el «ser com a presència» $\mathrm{i}$ el «ser com a absència». De forma entrelligada, Derrida hi afegeix que aquesta partició és, al seu torn, el resultat d'una distinció entre la parla i l'escriptura. Si la cultura occidental ha malfiat sempre del signe escrit és perquè quan parlem ho fem amb presència (d'un mateix, de l'altre, de les coses); per tant, estem més a prop del seu veritable ser. Per aquest motiu, Derrida desconstrueix «les estructures logofonocèntriques del discurs tradicional d'Occident" (De Peretti, 1997: 144). D'aquella divisió fonamental, n'haurien sorgit moltes de les parelles binàries que utilitzem per definir i concebre les coses: vida/mort, ànima/cos, intel.ligible/sensible, raó/emoció, cultura/natura, home/dona, etc. I sempre, en cada una d'aquestes parelles, un dels dos termes seria el terme "present», idèntic a si mateix, original, mentre que l'altre no seria res més que una definició negativa del primer (si la raó és racional, les emocions són irracionals).

En qualsevol cas, ens diu Manuel Asensi, «el fonament de la metafísica es desprèn de la barra mateixa de l'oposició (/), una barra que incomunica els elements que entaulen una relació jeràrquica» (Asensi, 2004: 12). Amb això ens podem fer una idea més clara de com, a través de l'acte geogràfic de dibuixar línies, s'ha fundat el logos occidental — metafísica de la presència per Heidegger, del logocentrisme per Derrida.

I és en aquest punt on intervé de nou Farinelli. No només perquè, segons aquest autor, "la lògica binària neix sobre una taula [un mapa], on un signe és 
o no és», sinó perquè per a ell logos i raó cartogràfica són termes intercanviables (Farinelli, 2011). De fet, l'origen d'aquest intercanvi s'hauria produït durant el segle sisè abans de Crist, quan Anaximandre representà per primera vegada sobre un disc (pinax) el món conegut $\mathrm{i}$, al mateix temps, seguint la lògica geomètrica d'aquesta mateixa representació, elaborà una teoria de l'estabilitat de la Terra no en termes cosmogònics, sinó, justament, cosmològics —és a dir: lògics, raonats (Barnes, 1992). És per això que Farinelli pot sostenir que «logos $\mathrm{i}$ table [pinax, mapa] són la mateixa cosa $\mathrm{i}$, per tant, que el pensament occidental (raó) no és res més que el protocol de la representació cartogràfica, de la imatge cartogràfica». $\mathrm{O}$, més sintèticament, afirmar en un paràgraf més enllà: «La raó occidental no és res més que la raó cartogràfica» (Farinelli, 1998: 135). Per tant, l'interès de Farinelli per excavar i descalçar la nostra racionalitat (logos) és similar al moviment de Derrida; però, així com aquest darrer du a terme una desconstrucció del logos o del logocentrisme, aquell ens parla d'una crítica a la raó cartogràfica. En qualsevol cas, però, la definició de la desconstrucció com una "crítica total de la raó» de Thomas McCarthy és, al nostre parer, igualment vàlida per al treball de Franco Farinelli (McCarthy, 1989: 22).

La sintonia entre un pensament i l'altre no s'esgota en aquest punt. Va del ritme general al detall particular. Plegats realitzen un llarg recorregut, i plegats adopten també estratègies puntuals similars. Farinelli se centra igualment en el detall periferic. Es mou en els marges. Busca el revés dels mapes. Només per posar-ne un exemple a l'atzar. «Hom podria objectar — escriu el geògraf de Bolonya - que la moneda i la moderna representació geogràfica no són la mateixa cosa, perquè mentre que la primera té dues cares, el mapa només en té una: no té revés. Però aquest seria justament l'error». No fixar-se en el detall revelador del revés del mapa és un error, perquè és justament el que és a sota, l'altra cara del mapa, el que domina la forma moderna de representació cartogràfica. Si l'anvers «representa la versió espacial del món», diu Farinelli, el revés ens indica la naturalesa de l'espai:

Val a dir, una extensió pura que no significa en absolut el buit, sinó la totalitat de les coses, de la mateixa manera que el color blanc no significa l'absència sinó la totalitat dels colors. I el blanc, i només aparentment el buit del darrere del mapa, reflecteix la totalitat de les coses perquè expressa i conté de la manera més clara i simple el conjunt de les propietats del territori modern, que són, al cap i a la fi, les mateixes que Euclides assignava a l'extensió geomètrica en general: la continuïtat, l'homogeneïtat, la isotropia. (Farinelli, 2001a: 13-14)

I si Farinelli revisa el que és central i periferic en la història de la cartografia, de la mateixa manera que estableix connexions inesperades entre imatges gràfiques o busca el significat de les coses en etimologies remotes, gestos propis tots de la desconstrucció de Derrida, com hem vist, encara que no exclusius d'aquesta, també és cert que se n'aparta en alguns casos. Una doble confusió travessa part de la seva obra. Tot i que fa un primer pas desconstructiu (ja ho hem vist: el mapa precedeix el territori), és, d'altra banda, presoner del fonocentrisme, en la mesura que assimila el mapa a la mort (esquema inert, estàtic, 
rigor mortis) (Farinelli, 2002: 226; Farinelli, 2007: 12). No hem de veure, en aquest joc d'identificacions, el record d'aquesta tradició que hem recorregut breument segons la qual la parla oral, dialògica, és més viva perquè actua allà on és el món, en presència de rius i muntanyes, boscos i fondalades?

Només si partim d'aquest supòsit, és a dir, que Anaximandre hauria «gosat per primera vegada fixar i, per tant, matar, amb la seva escultura filosòfica [el pinax, el mapa], la naturalesa, que pels grecs era evolució i moviment perpetu", aleshores podem entendre per què el mateix Farinelli anuncia que, ja des de l'inici del coneixement occidental, és a dir, del logos, «a la cosa-en-si de Kant la substitueix el fenomen» (Farinelli, 2007: 12; Farinelli, 2005: 48). Segona confusió. En altres paraules, i per concloure aquest punt: a pesar de capgirar la jerarquia inicial del signe cartogràfic, Farinelli no esborra la barra metafísica que escindeix el significant del significat. Com a conseqüència d'això, es veu implicat en una trama d'oposicions binàries que el reté a l'interior de la tradició: el mapa com a símptoma de la mort, de la interrupció del flux vital del món, del silenci; o el mapa com a ocultació de la cosa-en-si, del veritable ésser de les coses, la pantalla que ens retorna només l'aparença del que és real.

Hem vist fins ara les similituds entre la desconstrucció de Derrida i la crítica a la raó cartogràfica de Farinelli, però també hem mostrat que, en alguns punts, aquesta darrera crítica refâ alguns nusos conceptuals que, justament, la desconstrucció havia volgut desfer. Tancarem aquest apartat amb una observació de caràcter general que pot recaure igual tant en l'una com en l'altra.

Escriu Farinelli: «La crítica de la raó cartogràfica es basa, sobretot, en el reconeixement que el secret de tot el coneixement occidental reposa sobre la projecció [cartogràfica]» (Farinelli, 2001b: 239). Per aquest autor, tot el coneixement occidental, que ja hem vist que identifica amb el logos, és el resultat dels passos, les tècniques o les idees necessàries per traslladar l'esfera terrestre sobre el pla. És certament una afirmació arriscada en la mesura que es tracta del resultat d'una síntesi i una reducció que és, al mateix temps, admirable i polèmica. De fet, una polèmica similar gira al voltant de la desconstrucció. Per Hilary Puntman «els desconstruccionistes tenen raó quan afirmen que certa tradició filosòfica està en decadència, però identificar aquesta tradició filosòfica amb les nostres vides i el nostre llenguatge suposa donar a la metafísica una importància exagerada. Per ells, la metafísica és la base de tota la nostra cultura, el pedestal sobre el qual reposa tot, i si aquesta està [en runes], tota la cultura s'ha hagut d'ensorrar (de fet, tot el nostre llenguatge ha d'estar en runes)» (Putnam, 1994: 181). Un altre autor, Thomas McCarthy, arriba a una conclusió similar: si per Derrida la desconstrucció té una dimensió política, diu, és perquè està convençut sobre el fet que la filosofia es troba al centre de la nostra cultura, en la mesura que és "constitutiva de la ciència i la cultura occidental, de la seva llengua i la seva literatura, de la seva política i la seva societat, del seu etnocentrisme i del seu imperialisme» (McCarthy, 1989: 181).

Tot i que no descartem la possibilitat que, efectivament, tot el coneixement occidental es basi en el problema geogràfic de com representem la Terra sobre el pla, no podem deixar-nos de preguntar si Farinelli atribueix a la cartografia 
una «importància exagerada», ja que, així com per Derrida la metafísica hauria dominat les «nostres vides» $\mathrm{i}$ el «nostre llenguatge», també per Farinelli gairebé tot es pot atribuir a aquell pecat original que Anaximandre cometé a la ciutat de Milet i que, uns quants segles més tard, el també geògraf $\mathrm{i}$ astrònom alexandrí Ptolomeu li donaria la forma i els atributs que avui en dia admirem i reconeixem. D'entrada, una cosa és certa: Occident tampoc no existeix.

\section{Plegar el mapa}

A través de l'expressió «desconstruir el mapa», que utilitzà per primera vegada Brian Harley seguint el filòsof Jacques Derrida, hem relacionat algunes idees que ens permeten afirmar que entre aquells i el també geògraf Franco Farinelli existeix un cert aire de família. Tot i que el darrer mai no ha plantejat la seva crítica a la raó cartogràfica en termes d'una desconstrucció del mapa, des del nostre punt de vista, alguns dels seus escrits contenen certs elements estructurals molt similars al projecte general de la desconstrucció de Derrida, un projecte que s'ha definint com una "crítica total a la raó». Si bé, com hem argumentat, és Farinelli l'autor que ha portat més lluny una desconstrucció del mapa, tot i això a l'interior dels seus textos hi hem observat alguns nusos argumentals que s'organitzen a partir d'aquelles dicotomies que, justament, la desconstrucció del filòsof francès havia posat entre parèntesis. Finalment, seguint les crítiques que s'han fet de forma general a la desconstrucció, hem plantejat que aquestes mateixes crítiques es poden traslladar al treball de Farinelli, sense deixar d'apreciar, això sí, el gran esforç de síntesi, imaginació i intel-ligència que la crítica a la raó cartogràfica representa.

\section{Referències bibliogràfiques}

Abbagno, Nicola (2008). Diccionario de filosofía. Mèxic: Fondo de Cultura Económica.

Alonso, Álvaro (2006). «Cervantes y los mapas: la cartografía como metáfora». Lectura y Signo, 1, 75-88.

AsENSI, Manuel (2004). «¿Qué es la deconstrucción de Jaques Derrida?». Visions de l'Escola Tècnica Superior d'Arquitectura, 3, 11-19.

BARNES, Jonathan (1992). Los presocráticos. Madrid: Cátedra.

Belyea, Barbara (1992). «Images of Power: Derrida/Foucault/Harley». Cartographica, 29 (2), 1-9.

Benach, Núria i Albet, Abel (2010). Edward W. Soja: La perspectiva postmoderna de un geógrafo radical. Barcelona: Icaria.

Cosgrove, Denis (2005). «Maps, Mapping, Modernity: Art and Cartography in the Twentieth Century». Imago Mundi, 57 (1), 35-54.

Crampton, Jeremy W. (2002). «Thinking Philosphically in Cartography: Toward A Critical Politics of Mapping». Cartographic Perspectives, 42, 12-31.

- (2010). Mapping: A critical introduction to Cartography and GIS. Oxford: WileyBlackwell.

Culler, Jonathan (1998). Sobre la deconstrucción: Teoría y crítica después del estructuralismo. Madrid: Cátedra. 
De Peretti, Cristina (1997). «Deconstrucción». A: Ortiz-Osés, A. i Lanceros, P. (dirs.). Diccionario interdisciplinar de Hermeneútica. Bilbao: Universidad de Deusto.

De Sousa Santos, Boaventura (2000). Critica a la razón indolente. Contra el desperdicio de la experiencia. Para un nuevo sentido común: la ciencia, el derecho y la politica en la transición paradigmática. Bilbao: Desclée de Brouwer.

Dent, Nicholas (2008). «Logos». A: Honderich, Ted (ed.). Enciclopedia Oxford de Filosofía. Madrid: Tecnos, 719.

Derrida, Jacques (1977). «Semiología y gramatología. Entrevista con Julia Kristeva». A: Derrida, Jacques. Posiciones. València: Pre-textos, 23-47.

- (2003). De la gramatología. Mèxic: Siglo XXI.

- (1989). La desconstrucción en las fronteras de la filosofía: La retirada de la metáfora. Barcelona: Paidós/ICE-UAB.

FARINELli, Franco (1998). «Did Anaximander ever Say (or Write) any Words? The Nature of Cartographical Reason». Ethics, Place and Environment, 1 (2), 135-144.

- (2001a). «La moneta, la mappa, il globo». A: FArinelli, Franco (ed.). Una Europa una moneta. Bolonya: Pendragon, 9-16.

- (2001b). "Mapping the Global, or the Metaquantum Economics of Myth». A: Minca, Claudio (ed.). Postmodern Geography. Theory and Praxis. Oxford: Blackwell Publishers, 238-254.

- (2002). "Il mondo, la mappa, il labirinto». A: Bocchi, Gianluca i Ceruti, Mauro (coord.). Origini della scrittura: genealogie di un'invenzione. Milà: Bruno Mondadori, 225-234.

- (2005). «El mundo, el globo, el mapa: los orígenes de la modernidad». A: Jarauta, Francisco (ed.). El mundo de los mapas. Santander: Fundación Marcelino Botín, 41-56.

- (2007). «La razón cartográfica, o el nacimiento de Occidente». Revista de Occidente, 314-315, 5-18.

- (2011). «L'ossessione delle Mappe». La Repubblica, 11 de gener, 57.

Ferraris, Maurizio (2006). Introducción a Derrida. Buenos Aires: Amorrortu.

Goldschmit, Marc (2004). Jacques Derrida, una introducción. Buenos Aires: Nueva Visión.

Harley, Brian (1990). «Cartography, Ethics and Social Theory». Cartographica, 27 (2), 1-23.

- (2005a). «Hacia una deconstrucción del mapa». A: Harley, Brian. La nueva naturaleza de los mapas: Ensayos sobre la historia de la cartografía. Mèxic: Fondo de Cultura Econòmica, 185-207.

- (2005b). «Mapas, conocimiento y poder». A: Harley, Brian. La nueva naturaleza de los mapas: Ensayos sobre la historia de la cartografia. Mèxic: Fondo de Cultura Económica, 79-112.

Hoy, David (1988). "Jaques Derrida». A: Skinner, Quentin. El retorno de la Gran Teoría en las ciencias humanas. Madrid: Alianza Universidad, 48-69.

Jenkins, Keith (2006). ¿Por qué la historia?: Ética y postmodernidad. Mèxic: Fondo de Cultura Económica.

Klinghoffer, Arthur Jay (2006). The Power of Projections: How Maps Reflect Global Politics and History. Londres: Praeger.

LeCHTE, John (2010). 50 pensadores contemporáneos esenciales: Del estructuralismo al posthumanismo. Madrid: Cátedra.

Lilley, Keith (2004). «J. Brian Harley». A: Hubbard, Phil; Kitchin, Rob i Valentie, Gill (eds.). Key Thinkers on Space and Place. Londres: Sage Publications, 174-180. 
McCarthy, Thomas (1989). "La política de lo inafable: el deconstruccionismo de Derrida». La Balsa de la Medusa, 12, 17-42.

Peñalver, Patricio (1989). «Introducción». A: Derrida, Jacques. La desconstrucción en las fronteras de la filosofía: La retirada de la metáfora. Barcelona: Paidós/ICE-UAB.

Pickles, John (2004). A History of Spaces: Cartographic reason, mapping and the geocoded world. Londres: Routledge.

Putnam, Hilary (1994). Cómo renovar la filosofía. Madrid: Cátedra.

RAMOnD, Charles (2009). "Deconstrucción y literatura (Glas, una guía de lectura)». A: Ramond, Charles (coord.). Derrida: la deconstrucción. Buenos Aires: Nueva Visión, 73-107.

SALANSKIS, Jean-Michel (2009). "La filosofía de Jacques Derrida y la especificidad de la deconstrucción en el seno de las filosofías del linguistic turn». A: Ramond, Charles (coord.). Derrida: la deconstrucción. Buenos Aires: Nueva Visión, 7-35.

WeIgel, Sigrid (2009). "On the "Topographical Turn": Concepts of Space in Cultural Studies and Kulturwissenschaften. A Cartographic Feud». European Review, 17 (1), 187-201.

Zumthor, Paul (1994). La medida del mundo. Madrid: Cátedra. 